\title{
Promotive effect of Shoyu polysaccharides from soy sauce on iron absorption in animals and humans
}

\author{
MAKIO KOBAYASHI ${ }^{1,2}$, YUKO NAGATANI ${ }^{1}$, NORIHIRO MAGISHI ${ }^{1}$, NOZOMU TOKURIKI $^{1}$, \\ YOSHIYUKI NAKATA ${ }^{1}$, RYO-ICHI TSUKIYAMA ${ }^{1}$, HIROMI IMAI ${ }^{2}$, MAKOTO SUZUKI $^{2}$, \\ MASAMI SAITO ${ }^{3}$ and KEISUKE TSUJI ${ }^{2}$ \\ ${ }^{1}$ Research Laboratory, Higashimaru Shoyu Co., Ltd., Tominaga, Tatsuno, Hyogo 679-4167; ${ }^{2}$ School of Human \\ Science and Environment, University of Hyogo, Shinzaike-honcho, Himeji, Hyogo 670-0092; ${ }^{3}$ Institute of \\ General Health Development Co., Ltd., Shiba-Daimon, Minato-ku, Tokyo 105-0012, Japan
}

Received July 11, 2006; Accepted August 28, 2006

\begin{abstract}
Soy sauce (Shoyu) is a traditional fermented seasoning of Japan and is available throughout the world. We investigated the effect of Shoyu polysaccharides (SPS) prepared from soy sauce on iron absorption in vitro and in vivo. First, by measuring the iron-binding capacity of SPS, it was found that SPS stabilized the solubility of ferrous iron at neutral $\mathrm{pH}$ 's by forming a complex, Fe-SPS. Second, in experiments with animals, it was found that SPS enhanced the absorption and/or pooling of iron in organs when anemic rats were fed iron-supplemented diets. Third, in a 4-week randomized, double-blind, placebo-controlled parallel group study, healthy women were treated with $600 \mathrm{mg}$ of SPS $(n=22)$ or placebo $(n=23)$ each day. After the 4 weeks, serum levels of iron, hematocrit, and hemoglobin were significantly higher $(\mathrm{P}<0.05)$ in the SPS-treated than in the placebo-treated group. In conclusion, SPS of soy sauce enhanced iron absorption, and soy sauce is a potentially promising seasoning for the treatment of anemia through food.
\end{abstract}

\section{Introduction}

Soy sauce (Shoyu) is a traditional fermented seasoning of Japan available throughout the world (1). In Japanese shoyu, soybeans and wheat are the two main raw materials, used in almost the same quantity. Proteins of the raw materials are completely degraded into peptides and amino acids by microbial proteolytic enzymes after fermentation, and no allergens of the raw materials are present in soy sauce (2). In

Correspondence to: Dr Makio Kobayashi, Research Laboratory, Higashimaru Shoyu Co., Ltd., 100-3 Tominaga, Tatsuno-cho, Tatsuno, Hyogo 679-4167, Japan

E-mail: mkobayashi@higashimaru.co.jp

Key words: anemia, chelating activity, iron absorption, Shoyu polysaccharides, soy sauce contrast, polysaccharides that originate from the cell wall of soybeans are resistant to enzymatic hydrolysis; these polysaccharides remain in soy sauce even after fermentation and are termed shoyu polysaccharides (SPS) (3). Recently, we reported that SPS have strong anti-allergic activities (3) and enhance the functions of macrophages and lymphocytes (4) in vitro and in vivo. Furthermore, oral supplementation with SPS was an effective intervention for patients with allergic rhinitis in two double-blind placebo-controlled clinical studies $(5,6)$. However, many of the ingredients of soy sauce are unknown and the biological activities of soy sauce itself remain to be elucidated. Although soy sauce has been reported to have anti-carcinogenic $(7,8)$, anti-microbial (9), anti-oxidative (10-12), and anti-platelet (13) activities, and to inhibit angiotensin I-converting enzyme (14), further study is necessary to elucidate the biological functions of soy sauce itself and the ingredients it contains.

Iron deficiency anemia is an urgent nutritional problem, and the fortification of food is considered an indispensable approach to eliminating this anemia from Asia. Soy sauce is a popular traditional seasoning in China, Thailand, and Vietnam, making it a candidate for use as an iron carrier. Baynes et al (15) first reported the promotive effect of Fefortified soy sauce on iron absorption in clinical studies in 1990. Thereafter, the successful use of Fe-fortified soy sauce and fish sauce in anemic women and children was reported in China $(16,17)$, Thailand $(18,19)$, and Vietnam $(20,21)$. However, the mechanism of soy sauce's promotive effect on iron absorption remains unclear (15). Therefore, in the present study, we examined the capacity of SPS to bind iron as well as the effect of SPS on iron absorption in animals and humans in order to clarify the promoting activities of SPS as a functional dietary component from soy sauce.

\section{Materials and methods}

Preparation of Shoyu polysaccharides (SPS). Soy sauce (Shoyu) was fermented by Higashimaru Shoyu Co., Ltd. (Tatsuno, Hyogo, Japan) as described previously $(1,2)$. Shoyu polysaccharides (SPS) were prepared according to the 
method of Kikuchi and Sugimoto (22). SPS were prepared for the dialysate from soy sauce as follows (3): $10 \mathrm{ml}$ of soy sauce in seamless cellulose tubing (small size 18; pore size, $25 \AA$; molecular weight cut-off, 12,000; Wako Pure Chemical Industries Ltd., Osaka, Japan) was dialyzed overnight in water at $4^{\circ} \mathrm{C}$, and then freeze-dried.

In vitro Fe-binding capacity of SPS. The Fe-binding capacity of SPS was measured by the equilibrium method in vitro as described by Tsuji et al (23). In a 300-ml glass beaker, SPS and $\mathrm{FeSO}_{4} \cdot \mathrm{H}_{2} \mathrm{O}$ were dissolved in $200 \mathrm{ml}$ of distilled water to final concentrations of $10 \mathrm{mg} / \mathrm{ml}$ (SPS) and $300 \mu \mathrm{g} / \mathrm{ml}(\mathrm{Fe})$, respectively. In the solution, seamless cellulose tubing (small size 18; pore size, $25 \AA$; molecular weight cut-off, 12,000; Wako Pure Chemical Industries Ltd.) filled with $10 \mathrm{ml}$ of distilled water was soaked for $2 \mathrm{~h}$ at room temperature, and the dialysate in the tubing was obtained. The iron content of the inner solution was determined with a polarized Zeeman atomic absorption spectrophotometer (Z-2300, Hitachi High Technologies Co., Tokyo, Japan).

Animal experiments. The basal diet (CE-2) was purchased from CLEA Japan, Inc. (Tokyo, Japan). The iron-deficient diet (F2FeDD) was purchased from Oriental Yeast Co., Ltd. (Tokyo, Japan). F2FeDD contained $1.8 \mu \mathrm{g} / \mathrm{g}$ of iron as measured with the Z-2300 spectrophotometer.

Male SD rats (three weeks old) weighing 40-50 g were obtained from CLEA Japan, Inc., and bred in our laboratories. They were housed individually in cages under a $12-\mathrm{h}$ light/dark cycle at a temperature of $23 \pm 1^{\circ} \mathrm{C}$ and a humidity of $60 \pm 5 \%$. Anemia was induced in the rats by feeding them F2FeDD containing $1.8 \mu \mathrm{g} / \mathrm{g}$ of iron for 2 weeks $(24,25)$. Anemic rats were randomly divided into four groups of six, and continued on the F2FeDD diet supplemented with $\mathrm{FeSO}_{4} \cdot 7 \mathrm{H}_{2} \mathrm{O}$ and/or SPS: (A) no supplementation, (B) $\mathrm{FeSO}_{4}$. $7 \mathrm{H}_{2} \mathrm{O}$, (C) SPS, and (D) $\mathrm{FeSO}_{4} \cdot 7 \mathrm{H}_{2} \mathrm{O}$ and SPS. Concentrations of $\mathrm{Fe}$ and SPS were 4.236 and $60 \mathrm{mg} / 100 \mathrm{~g}$ of diet, respectively. The Fe content was the same as in the basal diet. Deionized water and the diets were provided daily ad libitum.

Samples of blood were collected in heparinized tubes from the caudal vein at intervals. Part of each sample was used to determine hemoglobin $(\mathrm{Hb})$ and hematocrit $(\mathrm{Ht})$ levels. $\mathrm{Hb}$ was measured with a commercial kit (Wako Pure Chemical Industries Ltd.), and Ht was determined by centrifugation $(12,000 \mathrm{rpm} \times 5 \mathrm{~min})$ using microhematocrit capillary tubes (Haematocrit-capillaries, Hirschmann Laborgerate, Germany). After 2 weeks on the diets, the rats were sacrificed, blood was collected from the abdominal aorta, and the organs were removed. Serum iron (SI), unsaturated iron binding capacity (UIBC), and total iron binding capacity (TIBC) were determined by Hyogo Clinical Laboratory Co. (Himeji, Hyogo, Japan). Iron saturation (IS) was calculated using the following formula: IS $(\%)=($ SI $x$ 100)/TIBC. Organ iron content was determined with the Z-2300 spectrophotometer.

Clinical studies. We enrolled 45 apparently healthy women aged 20-60 years. Exclusion criteria included pregnancy or lactation and known gastrointestinal or metabolic disorders.
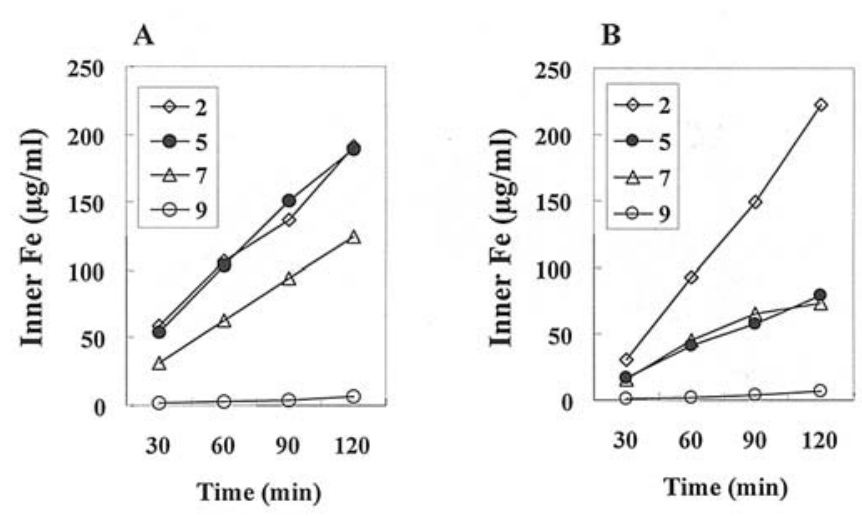

Figure 1 . Fe diffused into the inner solution by dialysis across the cellulose membrane at several pH's without SPS (A), and with $10 \mathrm{mg} / \mathrm{ml}$ of SPS (B). In a 300-ml glass beaker, $200 \mathrm{ml}$ of distilled water was added, and then $\mathrm{FeSO}_{4} \cdot 7 \mathrm{H}_{2} \mathrm{O}$ was dissolved (the outer solution, $300 \mu \mathrm{g} / \mathrm{ml}$ of $\mathrm{Fe}$ ). The $\mathrm{pH}$ of the outer solution was adjusted to between 2.0 and 9.0 with $1 \mathrm{M} \mathrm{HCl}$ and $\mathrm{NaOH}$. In the solution, seamless cellulose tubing filled with $10 \mathrm{ml}$ of distilled water was put into the outer solution. Dialysis of Fe into the inner solution was measured as a function of time. The Fe content was determined with an atomic absorption spectrophotometer.

Patients were fully informed regarding the experimental procedures, and written consent was obtained. Safety was monitored using clinical history, physical examinations, and routine blood tests, including hepatic and renal function tests and complete blood counts.

The study used a randomized, double-blind, placebocontrolled parallel group design. The protocol was approved by the ethics committees of the participating hospitals. The study was managed and operated by the Institute of General Health Development Co., Ltd. (Tokyo, Japan) in accordance with the Declaration of Helsinki. The trial was carried out for 4 weeks.

Of the 45 patients, 22 were randomized to the SPS group (average age, $44.3 \pm 7.0$ ) and 23 to the placebo group (average

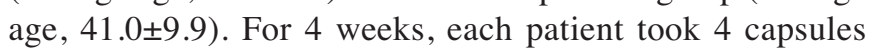
daily ( 2 capsules each morning and evening). SPS were prepared from an ethanol precipitate of raw soy sauce as described previously (3-6). SPS powder was encapsulated into gelatin capsules (hard type, size 3, dark caramel; Sankyo Co., Ltd., Fuji, Shizuoka, Japan). The test capsules were made with $150 \mathrm{mg}$ of SPS, $60 \mathrm{mg}$ of microcrystalline cellulose, $15 \mathrm{mg}$ of sucrose esters of fatty acids, and $5 \mathrm{mg}$ of silicon dioxide per capsule. The placebo capsules were made in the same manner as the test capsules but without SPS. The capsules were indistinguishable between groups.

All blood tests were conducted by SRL Inc. (Tachikawa, Tokyo, Japan). Routine blood testing, including complete blood cell counts, examinations of hepatic and renal function, and measurements of concentrations of proteins and lipids, was also performed. Notably, the red blood cell (RBC), Ht, $\mathrm{Hb}$, and SI values for blood samples were measured by SRL Inc. according to an analytical protocol.

Statistical analyses. Data were analyzed using SPSS for Windows 7.5.1 (SPSS Japan Inc., Tokyo, Japan). Differences in data were evaluated between groups with a Tukey's test or a Student's t-test. $\mathrm{P}<0.05$ was considered statistically significant. 
Table I. Food intake, body weight, and organ weights in anemic rats after 2 weeks on the diets.

\begin{tabular}{lcccc}
\hline Dietary group & & $\mathrm{B}$ & $\mathrm{C}$ & $\mathrm{D}$ \\
\hline Food intake (g/day) & $\mathrm{A}$ & $23.9 \pm 1.1^{\mathrm{b}}$ & $15.8 \pm 0.5^{\mathrm{a}}$ & $24.1 \pm 0.7^{\mathrm{b}}$ \\
Body weight (g) & $15.4 \pm 0.2^{\mathrm{a}}$ & $275 \pm 7^{\mathrm{b}}$ & $209 \pm 4^{\mathrm{a}}$ & $279 \pm 5^{\mathrm{b}}$ \\
Organ weights (g) & $217 \pm 6^{\mathrm{a}}$ & & & \\
Liver & & $14.60 \pm 0.50^{\mathrm{b}}$ & $7.40 \pm 0.10^{\mathrm{c}}$ & $14.60 \pm 0.50^{\mathrm{b}}$ \\
Heart & $8.00 \pm 0.10^{\mathrm{a}}$ & $1.06 \pm 0.04^{\mathrm{b}}$ & $1.38 \pm 0.06^{\mathrm{a}}$ & $1.07 \pm 0.03^{\mathrm{b}}$ \\
Kidneys & $1.58 \pm 0.12^{\mathrm{a}}$ & $2.47 \pm 0.08^{\mathrm{b}}$ & $2.03 \pm 0.07^{\mathrm{a}}$ & $2.39 \pm 0.12^{\mathrm{b}}$ \\
Spleen & $2.01 \pm 0.10^{\mathrm{a}}$ & $0.82 \pm 0.03^{\mathrm{a}}$ & $0.68 \pm 0.03^{\mathrm{b}}$ & $1.01 \pm 0.08^{\mathrm{c}}$ \\
Lungs & $0.75 \pm 0.04^{\mathrm{ab}}$ & $1.28 \pm 0.07^{\mathrm{ab}}$ & $1.13 \pm 0.04^{\mathrm{b}}$ & $1.28 \pm 0.05^{\mathrm{ab}}$ \\
Testicles & $1.30 \pm 0.04^{\mathrm{a}}$ & $2.54 \pm 0.07$ & $2.41 \pm 0.07$ & $2.42 \pm 0.05$ \\
Epididymis & $2.62 \pm 0.11$ & $0.09 \pm 0.01$ & $0.09 \pm 0.01$ & $0.11 \pm 0.01$ \\
Stomach & $0.12 \pm 0.02$ & $2.89 \pm 0.54^{\mathrm{bc}}$ & $3.43 \pm 0.37^{\mathrm{b}}$ & $2.40 \pm 0.16^{\mathrm{c}}$ \\
Small intestine & $6.40 \pm 0.27^{\mathrm{a}}$ & $8.02 \pm 0.27^{\mathrm{a}}$ & $7.07 \pm 0.21^{\mathrm{b}}$ & $8.95 \pm 0.52^{\mathrm{a}}$ \\
Cecum & $8.64 \pm 0.39^{\mathrm{a}}$ & $4.39 \pm 0.20^{\mathrm{b}}$ & $5.09 \pm 0.23^{\mathrm{a}}$ & $5.25 \pm 0.22^{\mathrm{a}}$ \\
Thymus & $5.33 \pm 0.81^{\mathrm{ab}}$ & $0.63 \pm 0.06^{\mathrm{b}}$ & $0.48 \pm 0.03^{\mathrm{a}}$ & $0.68 \pm 0.05^{\mathrm{b}}$ \\
\hline
\end{tabular}

${ }^{1}$ Anemia was induced in the rats by feeding them the Fe-deficient diet (Fe2FeDD) for 2 weeks. After 2 weeks, the body weight of the anemic rats was $150 \pm 11 \mathrm{~g}$. The anemic rats were then randomly divided into four groups of six, and continued on F2FeDD supplemented with $\mathrm{FeSO}_{4} \cdot 7 \mathrm{H}_{2} \mathrm{O}$ and/or SPS: (A) no supplementation, (B) $\mathrm{FeSO}_{4} \cdot 7 \mathrm{H}_{2} \mathrm{O}$, (C) SPS, and (D) $\mathrm{FeSO}_{4} \cdot 7 \mathrm{H}_{2} \mathrm{O}$ and SPS. Concentrations of Fe and SPS were 4.236 and $60 \mathrm{mg} / 100 \mathrm{~g}$ of diet, respectively. After feeding for 2 weeks, the rats were sacrificed, and the organs were removed. Each value is the mean $\pm \mathrm{SE}(\mathrm{n}=6)$. Values with different superscripts differ, $\mathrm{P}<0.05$ (Tukey's test).

\section{Results}

In vitro Fe-binding capacity of SPS. Unlike heme iron, inorganic iron needs to be solubilized in the gastrointestinal tract to be effectively absorbed (26). First, we investigated the solubility of ferrous iron by SPS at several pH's. At pH 7, ferrous iron was precipitated in the absence of SPS, but not in the presence of $10 \mathrm{mg} / \mathrm{ml}$ of SPS (data not shown). Therefore, SPS increased the solubility of ferrous iron at neutral $\mathrm{pH}$ 's by chelating the iron. Second, we measured the Fe-binding capacity of SPS using the equilibrium method. $\mathrm{Fe}$ diffused into the inner solution by dialysis across the cellulose membrane at several pH's (Fig. 1). In the absence of SPS (Fig. 1A), the inner concentration of $\mathrm{Fe}$ at $\mathrm{pH} 5.0$ was the same as that at $\mathrm{pH} 2.0$, and the inner concentration at $\mathrm{pH} 7.0$ was decreased because of the precipitation of iron in the outer solutions. In contrast, in the presence of $10 \mathrm{mg} / \mathrm{ml}$ of SPS (Fig. 1B), the inner concentration of Fe at both $\mathrm{pH} 5.0$ and 7.0 was decreased remarkably compared to that at $\mathrm{pH} 2.0$. Under these conditions, the precipitation of iron did not occur. SPS were not able to dialyze into the inner solution because their molecular size was larger than the membrane cut-off size. Therefore, SPS stabilized the solubility of ferrous iron at neutral $\mathrm{pH}$ 's by forming the complex Fe-SPS.

Promotive effect of SPS on iron absorption in animals. After anemia was induced by feeding the rats the Fe-deficient diet for 2 weeks, anemic animals were randomly divided into four groups: (A) no supplementation, (B) Fe, (C) SPS, and (D) Fe + SPS. For 2 weeks, neither food intake nor body weight differed significantly between groups $\mathrm{A}$ and $\mathrm{C}$ or between groups $\mathrm{B}$ and $\mathrm{D}$, respectively (Table I). When anemia was continued by feeding the animals the Fe-deficient diets (A and C), SPS did not influence these parameters. When anemia was recovered by giving the Fe-supplemented diets (B and D), SPS did not influence these parameters.

After 2 weeks on the diets, the rats were sacrificed, and their organs were removed. Organ weights were significantly influenced by the Fe-supplementation, and the weights of the liver, kidneys, and thymus were significantly higher in group B than in group A (Table I). When the diet was supplemented with $\mathrm{Fe}+\mathrm{SPS}$, the weights of the liver, kidneys, spleen, small intestine, and thymus were significantly higher in group D than in group C. Among the organs affected by iron, the liver and spleen are representative iron-pooling organs. When anemia was recovered by feeding the animals the Fesupplemented diet (B and D), liver weights increased in both groups B and D, but spleen weights increased only in group D. Furthermore, levels of pooled iron in organs and excreted iron in feces were analyzed (Table II). When the anemia was recovered by administering the Fe-supplemented diet (B and D), iron levels in the liver and spleen were significantly increased. To note, when the diet was supplemented with $\mathrm{Fe}$ + SPS (D), the amount of iron in the liver was significantly higher than the level of Fe only (B), but that in feces was significantly lower than the concentration of Fe only (B). In contrast, $\mathrm{Hb}, \mathrm{Ht}$, SI, UIBC, TIBC, and IS differed significantly between the animals given the Fe-supplemented diets (B and D) and those given the Fe-deficient diets (A and C), but not between groups B and D (Table II). Therefore, SPS enhanced the absorption and/or pooling of iron in the organs when anemia was recovered with the Fe-supplemented diets.

Promotive effect of SPS on iron absorption in humans. Fortyfive women were enrolled in this study (22 in the SPS-treated group and 23 in the placebo-treated group) (Table III). In this 
Table II. Analyses of blood, organs, and feces in anemic rats after 2 weeks on the diets.

\begin{tabular}{|c|c|c|c|c|}
\hline Dietary group $^{1}$ & A & $\mathrm{B}$ & $\mathrm{C}$ & $\mathrm{D}$ \\
\hline Hemoglobin $(\mathrm{g} / \mathrm{dl})$ & $5.38 \pm 0.15^{\mathrm{a}}$ & $13.3 \pm 0.20^{\mathrm{b}}$ & $5.30 \pm 0.10^{\mathrm{a}}$ & $13.0 \pm 0.40^{\mathrm{b}}$ \\
\hline Hematocrit (\%) & $13.3 \pm 0.6^{\mathrm{a}}$ & $39.2 \pm 0.5^{\mathrm{b}}$ & $13.8 \pm 0.5^{\mathrm{a}}$ & $39.8 \pm 0.5^{b}$ \\
\hline \multicolumn{5}{|l|}{ Serum } \\
\hline Iron $(\mu \mathrm{g} / \mathrm{dl})$ & $16.6 \pm 1.1^{\mathrm{a}}$ & $283 \pm 21^{\mathrm{b}}$ & $19.3 \pm 0.8^{\mathrm{a}}$ & $275 \pm 34^{\mathrm{b}}$ \\
\hline $\mathrm{UIBC}(\mu \mathrm{g} / \mathrm{dl})$ & $984 \pm 21.6^{\mathrm{a}}$ & $324 \pm 151^{b}$ & $980 \pm 11^{\mathrm{a}}$ & $301 \pm 55^{\mathrm{b}}$ \\
\hline TIBC $(\mu \mathrm{g} / \mathrm{dl})$ & $1001 \pm 21.6^{\mathrm{a}}$ & $607 \pm 117^{\mathrm{b}}$ & $999 \pm 10^{\mathrm{a}}$ & $576 \pm 26^{b}$ \\
\hline Iron saturation (\%) & $1.66 \pm 0.12^{\mathrm{a}}$ & $46.6 \pm 9.9^{b}$ & $1.94 \pm 0.09^{\mathrm{a}}$ & $47.7 \pm 6.8^{b}$ \\
\hline \multicolumn{5}{|l|}{ Organ iron } \\
\hline Liver iron ( $\mu \mathrm{g} /$ liver $)$ & $10.9 \pm 0.9^{\mathrm{a}}$ & $14.7 \pm 1.6^{\mathrm{a}}$ & $7.2 \pm 0.5^{\mathrm{b}}$ & $22.4 \pm 2.4^{\mathrm{c}}$ \\
\hline Spleen iron $(\mu \mathrm{g} /$ spleen $)$ & $1.4 \pm 0.1^{\mathrm{a}}$ & $2.1 \pm 0.2^{\mathrm{bc}}$ & $1.5 \pm 0.2^{\mathrm{ab}}$ & $3.0 \pm 0.4^{\mathrm{c}}$ \\
\hline \multicolumn{5}{|l|}{ Feces at 14 days } \\
\hline Dry weight (g) & $0.98 \pm 0.10^{\mathrm{a}}$ & $1.91 \pm 0.06^{\mathrm{b}}$ & $1.12 \pm 0.08^{\mathrm{a}}$ & $1.88 \pm 0.07^{\mathrm{b}}$ \\
\hline Iron $(\mu \mathrm{g})$ & $1.29 \pm 0.05^{\mathrm{a}}$ & $69.33 \pm 0.17^{\mathrm{b}}$ & $1.64 \pm 0.06^{\mathrm{a}}$ & $41.74 \pm 0.26^{c}$ \\
\hline
\end{tabular}

Table III. Iron absorption by healthy adult women in SPS- and placebo-treated groups ${ }^{\mathrm{a}}$.

\begin{tabular}{lccc}
\hline Blood tests & Groups & Week 0 & Week 4 \\
\hline Red blood cell density & SPS & $440.64 \pm 38.15$ & $434.41 \pm 38.66$ \\
$(\mathrm{x} \mathrm{10} / \mu \mathrm{l})$ & Placebo & $425.73 \pm 26.05$ & $415.48 \pm 27.53$ \\
& t-test $^{\mathrm{b}}$ & $\mathrm{NS}$ & $\mathrm{NS}$ \\
Serum iron & SPS & $104.14 \pm 39.27$ & $117.45 \pm 48.60$ \\
$(\mu$ g/dl) & Placebo & $108.09 \pm 59.18$ & $91.65 \pm 33.44$ \\
& t-test & $\mathrm{NS}$ & $\mathrm{P}<0.05^{\mathrm{c}}$ \\
Hematocrit & SPS & $41.54 \pm 2.87$ & $40.60 \pm 2.65$ \\
$(\%)$ & Placebo & $39.36 \pm 2.89$ & $38.28 \pm 3.11$ \\
& t-test & $\mathrm{NS}$ & $\mathrm{P}<0.05^{\mathrm{c}}$ \\
Hemoglobin & SPS & $13.35 \pm 1.09$ & $13.18 \pm 1.05$ \\
$(\mathrm{~g} / \mathrm{dl})$ & Placebo & $12.71 \pm 1.21$ & $12.32 \pm 1.29$ \\
& t-test & $\mathrm{NS}$ & $\mathrm{P}<0.05^{\mathrm{c}}$ \\
\hline
\end{tabular}

${ }^{\text {aF }}$ Forty-five patients were enrolled in the study (22 in the SPS group and 23 in the placebo group, respectively). For 4 weeks, each patient took 4 capsules daily ( 2 capsules each morning and evening). The SPS capsules contained $150 \mathrm{mg}$ of SPS, but the placebo capsules contained no SPS. bifferences in blood data were evaluated between groups with the Student's t-test. ${ }^{\mathrm{c}} \mathrm{P}<0.05$ was considered statistically significant. NS, not significant. Data are presented as the mean \pm SD.

study, patients received iron from normal meals, and the diet was not supplemented with additional iron. Since SPS contain a very small amount of iron $(0.6 \mathrm{mg}$ of $\mathrm{Fe} / 600 \mathrm{mg}$ of SPS per day), the iron derived from SPS was negligible. There were no significant differences in the results of baseline blood tests for RBC, SI, Ht, and $\mathrm{Hb}$ among the groups. After 4 weeks of treatment, SI, Ht, and $\mathrm{Hb}$ were significantly higher in the SPS-treated group than in the placebo-treated controls. After 4 weeks of treatment, no significant abnormality was detected in routine blood tests, including hepatic and renal function, and concentrations of proteins and lipids (data not shown).

\section{Discussion}

Food fortification is considered the most cost-effective intervention to combat iron deficiency. In Southeast Asia, where iron deficiency is widespread, and a major public health 
problem, soy sauce may be a preferred food condiment for iron fortification with rice meals because of its consumption and costs $(15-21,27)$. Recent human studies have indicated that soy sauce would be a useful food vehicle for iron fortification in China $(16,17)$, Thailand $(18,19)$, and Vietnam $(20,21)$. Moreover, it was reported that soy sauce added to a rice meal appeared to enhance iron absorption whatever its mechanism of action (15). Although these findings may have some relevance to iron nutrition in those Asian countries where rice forms a substantial part of the staple diet, the mechanism promoting the effect of soy sauce on iron absorption remains unclear.

In this study, we indicated that SPS of soy sauce may function as an iron-chelator at neutral $\mathrm{pH}$ 's, for example, in the small intestine. Furthermore, SPS enhanced the absorption and/or pooling of iron in anemic rats after 2 weeks. In a clinical study of healthy women, SI, Ht, and $\mathrm{Hb}$ were significantly higher $(\mathrm{P}<0.05)$ in the SPS-administered group than in the placebo-administered group after 4 weeks of treatment. In conclusion, SPS of soy sauce act to enhance iron absorption by stabilizing gastrointestinal conditions. The amount of soy sauce consumed daily in Japan is estimated at about $30 \mathrm{ml}$ per person according to data from the Japan Soy Sauce Brewers Association (1988). In conclusion, soy sauce is useful as an anti-anemic in daily life, and the SPS from soy sauce are safe and act as a promoting agent for iron fortification of food. In our laboratories, a clinical study of SPS treatment for anemic women is now underway.

\section{Acknowledgments}

The authors are grateful to Dr Kohei Ushio (Research Laboratory, Higashimaru Shoyu Co., Ltd.) for his critical reading of the manuscript and helpful discussions. This work was supported in part by a subsidy from the Ministry of Agriculture, Forestry and Fisheries of Japan (Technical Development Program for making agribusiness in the form of utilizing the concentrated know-how from the private sector).

\section{References}

1. Yokotsuka T: Soy sauce biochemistry. Adv Food Res 30: 195-329, 1986.

2. Kobayashi M, Hashimoto $\mathrm{Y}$, Taniuchi $\mathrm{S}$ and Tanabe S: Degradation of wheat allergen in Japanese soy sauce. Int J Mol Med 13: 821-827, 2004.

3. Kobayashi M, Matsushita H, Yoshida K, Tsukiyama R, Sugimura T and Yamamoto K: In vitro and in vivo anti-allergic activity of soy sauce. Int J Mol Med 14: 879-884, 2004.

4. Matsushita H, Kobayashi M, Tsukiyama R and Yamamoto K: In vitro and in vivo immunomodulating activities of Shoyu polysaccharides from soy sauce. Int J Mol Med 17: 905-909, 2006.

5. Kobayashi M, Matsushita H, Shioya I, Nagai M, Tsukiyama R, Saito M, Sugita T, Sugimura T and Yamamoto K: Quality of life improvement with soy sauce ingredients, shoyu polysaccharides, in perennial allergic rhinitis: a double-blind placebo-controlled clinical study. Int J Mol Med 14: 885-889, 2004

6. Kobayashi M, Matsushita H, Tsukiyama R, Saito M and Sugita T: Shoyu polysaccharides from soy sauce improve quality of life for patients with seasonal allergic rhinitis: a double-blind placebo-controlled clinical study. Int J Mol Med 15: 463-467, 2005.

7. Benjamin H, Storkson J, Nagahara A and Pariza MW: Inhibition of benzo(a)pyrene-induced mouse forestomach neoplasia by dietary soy sauce. Cancer Res 51: 2940-2942, 1991.
8. Kataoka S, Liu W, Albright K, Storkson J and Pariza M: Inhibition of benzo[a]pyrene-induced mouse forestomach neoplasia and reduction of $\mathrm{H}_{2} \mathrm{O}_{2}$ concentration in human polymorphonuclear leucocytes by flavour components of Japanese-style fermented soy sauce. Food Chem Toxicol 35: 449-457, 1997.

9. Masuda S, Hara-Kudo Y and Kumagai S: Reduction of Escherichia coli $\mathrm{O} 157: \mathrm{H} 7$ populations in soy sauce, a fermented seasoning. J Food Prot 61: 657-661, 1998.

10. Long LH, Kwee DC and Halliwell B: The antioxidant activities of seasonings used in Asian cooking. Powerful antioxidant activity of dark soy sauce revealed using the ABTS assay. Free Radic Res 32: 181-186, 2000.

11. Harada K, Ando M, Kitao S, Sakamoto Y, Kobayashi M and Tamura Y: Measurement of antioxidative capacity of fish sauce using chemiluminescence method. Fish Sci 68 (suppl. 2): 1437-1440, 2002 .

12. Ando M, Harada K, Kitao S, Kobayashi M and Tamura Y: Relationship between peroxyl radical scavenging capability measured by the chemiluminescence method and an aminocarbonyl reaction product in soy sauce. Int J Mol Med 12: 923-928, 2003.

13. Tsuchiya H, Sato M and Watanabe I: Antiplatelet activity of soy sauce as functional seasoning. J Agric Food Chem 47: 4167-4174, 1999.

14. Kinoshita E, Yamakoshi J and Kikuchi M: Purification and identification of an angiotensin I-converting enzyme inhibitor from soy sauce. Biosci Biotechnol Biochem 57: 1107-1110, 1993.

15. Baynes RD, Macfarlane BJ, Bothwell TH, Siegenberg D, Bezwoda WR, Schmidt U, Lamparelli RD, Mayet F and MacPhail AP: The promotive effect of soy sauce on iron absorption in human subjects. Eur J Clin Nutr 44: 419-424, 1990.

16. Huo J, Sun J, Miao H, Yu B, Yang T, Liu Z, Lu C, Chen J, Zhang D, Ma Y, Wang A and Li Y: Therapeutic effects of NaFeEDTA-fortified soy sauce in anaemic children in China. Asia Pac J Clin Nutr 11: 123-127, 2002.

17. Chen J, Zhao X, Zhang X, Yin S, Piao J, Huo J, Yu B, Qu N, Lu Q, Wang $S$ and Chen C: Studies on the effectiveness of NaFeEDTA-fortified soy sauce in controlling iron deficiency: a population-based intervention trial. Food Nutr Bull 26: 177-189, 2005.

18. Walczyk T, Tuntipopipat S, Zeder C, Sirichakwal P, Wasantwisut $\mathrm{E}$ and Hurrell RF: Iron absorption by human subjects from different iron fortification compounds added to Thai fish sauce. Eur J Clin Nutr 59: 668-674, 2005.

19. Watanapaisantrakul R, Chavasit V and Kongkachuichai R: Fortification of soy sauce using various iron sources: sensory acceptability and shelf stability. Food Nutr Bull 27: 19-25, 2006.

20. Thuy PV, Berger J, Davidsson L, Khan NC, Lam NT, Cook JD, Hurrell RF and Khoi HH: Regular consumption of NaFeEDTAfortified fish sauce improves iron status and reduces the prevalence of anemia in anemic Vietnamese women. Am J Clin Nutr 78: 284-290, 2003.

21. Thuy PV, Berger J, Nakanishi Y, Khan NC, Lynch S and Dixon P: The use of NaFeEDTA-fortified fish sauce is an effective tool for controlling iron deficiency in women of childbearing age in rural Vietnam. J Nutr 135: 2596-2601, 2005.

22. Kikuchi T and Sugimoto H: Detailed structure of an acidic polysaccharide in soy sauce, confirmed by use of two kinds of purified pectinases. Agric Biol Chem 40: 87-92, 1976.

23. Tsuji K, Tsuji E, Nakagawa Y and Suzuki S: Effects of Nabinding capacity of dietary fibers on blood pressure in spontaneously hypertensive rats. J Home Econ Jpn 39: 187-195, 1988 (in Japanese).

24. Kawakami H, Hiratsuka M and Dosako S: Effects of ironsaturated lactoferrin on iron absorption. Agric Biol Chem 52: 903-908, 1988.

25. Igarashi K, Nakamura H, Nakanishi Y, Nakadai T, Okayasu M, Hirunuma R, Enomoto S and Kimura S: Efficacy of sodium iron ethylenediaminetetraacetic acid as a food fortifier for improving the iron-deficient status of anemic rats. J Jpn Soc Nutr Food Sci 57: 89-97, 2004 (in Japanese).

26. Kawakami H, Dosako S and Nakajima I: Effect of lactoferrin on iron solubility under neutral conditions. Biosci Biotech Biochem 57: 1376-1377, 1993.

27. Fidler MC, Davidsson L, Walczyk T and Hurrell RF: Iron absorption from fish sauce and soy sauce fortified with sodium iron EDTA. Am J Clin Nutr 78: 274-278, 2003. 